\title{
LESSONS FROM TWO DUTCH PROJECTS FOR THE INTRODUCTION OF COMPUTERS IN SCHOOLS
}

\author{
Alfons ten Brummelhuis and TJeerd Plomp \\ Department of Education, University of Twente, P.O. Box 217, 7500 AE Enschede, The Netherlands
}

(Received 7 October 1992; accepted 28 April 1993)

\begin{abstract}
The systematic introduction of computers in schools for general secondary education in The Netherlands started in the early 1980s. Initially, the Dutch government experimented in 1983 with a project in 100 lower general secondary schools limited in scope to gain experience with educational computer use (100-school project). In the period 1985-1989 the government implemented a second stimulation project focused at all lower secondary schools: New Information Technology in Secondary Education. This project consisted of the provision of hardware and courseware to all general secondary schools, organizing nationwide in-service teacher training, and the intensifying of software development.

With respect to the 100 -school project the question was whether there would be any differences in computer implementation and problems with computer use at schools in the 100-school project as compared to other schools which could only profit in the second promotional program.

The question addressed for the second promotional program concerns the use of software packages and courseware which were provided to all schools for general education during the NIVO-project.

An important conclusion for The Netherlands is, that the provision of hardware, software and in-service training was adequate to introduce computer education (called: information and computer literacy) as a new subject in nearly all lower secondary schools. But the set of stimulation activities does not seem to be adequate or sufficient to realize the integration of computer use in existing subjects.
\end{abstract}

\section{INTRODUCTION}

During the 1980s many governments in industrialized countries, amongst them The Netherlands, applied policies to stimulate the introduction of computers in education. Countries seldom have the opportunity of evaluating the effectiveness of such policies in a reliable way and with representative samples. Extensive evaluation studies are not often initiated by governments because of their time consuming character. Usually, policy makers cannot wait that long and want to determine the next step of such a policy when the current phase is not yet ended. The international comparative survey of 'Computers in Education' (Comped) of IEA (the International Association for the Evaluation of Educational Achievement), collected data in 1989 [1] and provided The Netherlands the opportunity to evaluate aspects of the stimulation policy.

The evaluation of two aspects of the Dutch stimulation policy on computers in education in the 1980s show that post-hoc several lessons can be learned from this exercise, which contribute to a better understanding of strategies which can be applied in similar situations.

\section{THE DUTCH STIMULATION POLICY}

In the 1980s, Dutch policy-making for the introduction of computers in secondary education took place via promotional programs [2]. The programs were different in emphasis: the 1982-1983 program had an exploratory character, while the 1985-1989 program could be characterized as basic provision and introduction of computers in the secondary schools.

\section{2-1983: exploration}

The first step was taken by the Dutch government in 1982 by starting the so-called ' 100 -schools project'[2]. This project was limited in scope, focusing on lower secondary education. All general secondary schools were invited to express their interest in this project; from which 100 schools were randomly selected to receive eight 8 -bit microcomputers and in-service training. As there was at that time little understanding of the possibilities of this new technology for education, the aims 
of the project were left open: 'let a thousand flowers bloom'. The government wanted strategic information on how schools were reacting to the challenge of the new technology, and what lessons could be learned from this. Schools were invited to focus first on the introduction of computer education (Information and Computer Literacy) as a new subject. As part of this project a curriculum development project in this area was established.

\section{5-1989: basic provision and introduction}

Before the first project ended and before any evaluation was conducted, the government announced its second promotional policy program, in which the tone of the stimulation policy was set by the Information Technology Stimulation Plan. Promotion assumed a totally different character [2]. Due mainly to the fear of falling behind economically, substantial budgets were set aside-in a time of government cuts - to promote information technology in society. All general secondary schools participated in 1985, as part of the stimulation policy, in the so-called NIVO project (New Information Technology in Secondary Education). This project, a collaboration of the government, computer manufacturers and educational umbrella organizations, consisted of the provision of hardware and courseware to all general secondary schools, organizing nationwide in-service teacher training, and the intensifying of software development. Almost 2000 general secondary schools were provided with a network of eight personal MS-DOS computers (it was suggested that schools would set up a special computer classroom or lab) and two stand-alone PC's in the period 1986-1988.

The primary goal of the NIVO-project was to introduce computer education as a new subject in all lower secondary schools and, secondly, to stimulate the integration of computer use in existing subjects. The schools in the ' 100 -school' project also belonged to the NIVO-project.

\section{Research questions}

With respect to the 100 -school project $(1982-1983)$ the question was whether the dialectics of progress would apply, that is whether there would be any differences in computer implementation and problems with computer use at schools in the 100 -school project (which can be seen as early adopters) as compared to other schools which could only profit in the second promotional program. The first program was focused on only 100 schools, the second program on all schools: would the forerunners be in a better position? If so, on what aspects? And if not, to what characteristic(s) of the innovative introduction of computers in school could this lack of effect possibly be contributed?

At the time the NIVO-project was launched, it was generally accepted that the introduction of computers in schools was hindered by three things: lack of hardware, lack of software and lack of knowledge of teachers. It was expected that addressing these needs in the project would be sufficient to get schools using computers in a variety of ways. To stimulate a quick start of educational computer use, the schools were given a starter pack of software consisting of packages

Table 1. Description of the software packages and courseware delivered to all secondary schools

\begin{tabular}{lc}
\hline Program & Description \\
\hline Sofware & Word processor for professional use \\
PC-TYPE & Universal database management program \\
PC-FILE & Spreadshet \\
PC-CALC & For creating bar graphs, pies, scattergrams, etc. \\
PC-GRAPH & Individual training programs for the PC \\
INSTRUCT & Authoring system for development of CAI programs \\
TAIGA & Program for free drawings \\
EGI & Simple version of CAD program \\
SUPERDRAFT & Educational game for 'developing' an invisible text \\
DOKA & Program for dynamic models: simulation \\
DMS & Examples of PC.CALC for six topics in physies \\
Courseware (lesson ideas) & Applications of PC-CALC in biology and earth science \\
PHYSICS & DMS application in biology (blood sugar and temperature) \\
BIOEART & Examples of PC-CALC application in mathematics \\
BIODMS & Examples of developing drill/practice CAI for foreign languages \\
MATH & with TAIGA \\
TAILANG & Examples of how to use DOKA for foreign language exercises \\
\hline
\end{tabular}


of open-ended framework programs with exemplery lessons (Table 1). The schools had to collect the software package at a regional center. The expectation was that by providing these packages to the schools, teachers would start to use them and to develop more lessons for their own use.

The research question addressed the use of the software packages and the courseware, or more specifically to what degree the materials were available in the schools, how and how often the packages and courseware were used and how teachers rate the quality of the available courseware. From this analysis we can obtain a better understanding of some of the characteristics of learning materials if authorities want to make them available without direct consultation of the schools as consumers. The results on this question are presented in Section 4.

\section{EVALUATION OF THE EXPLORATORY PROMOTIONAL PROGRAM}

In the Dutch Comped study, a sample of 500 out of nearly 2000 general secondary schools was selected. From this random sample 33 schools participated in the 100 -school project. From the other 67 schools that participated in the 100-school project, 13 were closed or merged with other schools between 1983 and 1989. The remaining 54 schools were added to the sample as a separate stratum. Altogether, 87 schools that participated in the 100-school project were asked for the Comped study, of which $58(67 \%)$ were willing to take part. The degree of participation in the total random sample was also $67 \%$.

The year of first computer use for the schools in the 100-school project is (on average) 1983. This means that most schools that participated in the 100 -school project received their first computer via this project. This is not surprising given the purpose and the time when the project started. The mean first year of computer use of the other schools is 1984. As the NIVO-project started in 1985, with the first delivery of hardware in 1986, these data mean that most schools in the NIVO project acquired their first computers from other scurces than the governmental promotional program. The Comped data[1] reveal for The Netherlands that by far the most important reasons for schools to introduce computers are, according to the principals, (1) students need experience with computers for their future, and (2) the teachers were interested. Apparently, most schools were not willing to wait for the government's policy plan for the period after the first exploratory program and started, under the pressure of enthusiastic teachers, to buy computers themselves.

Figure 1 shows the mean number of computers over the years $1985-1989$ for both groups. In 1985 the schools from the 100 -school project had on average two computers more than the other schools and in 1987 even three computers more. In 1988 the other schools had as many computers as the schools that participated in the 100-school project and in 1989 the other schools had three more computers than the schools that participated in the 100 -school project.

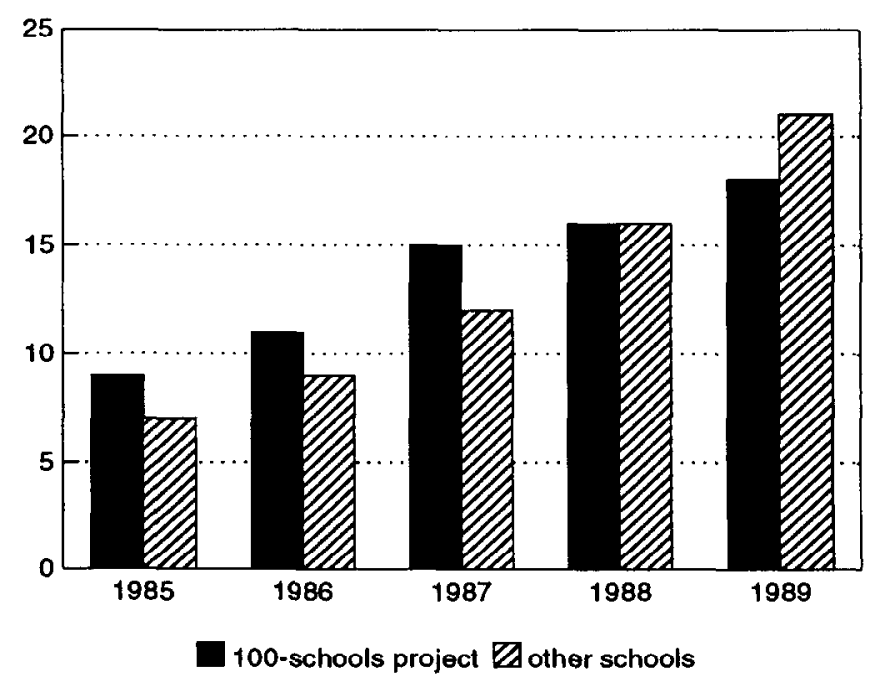

Fig. 1. Average number of computers at schools from the 100 -school project and other general secondary schools over the years 1985-1989. 


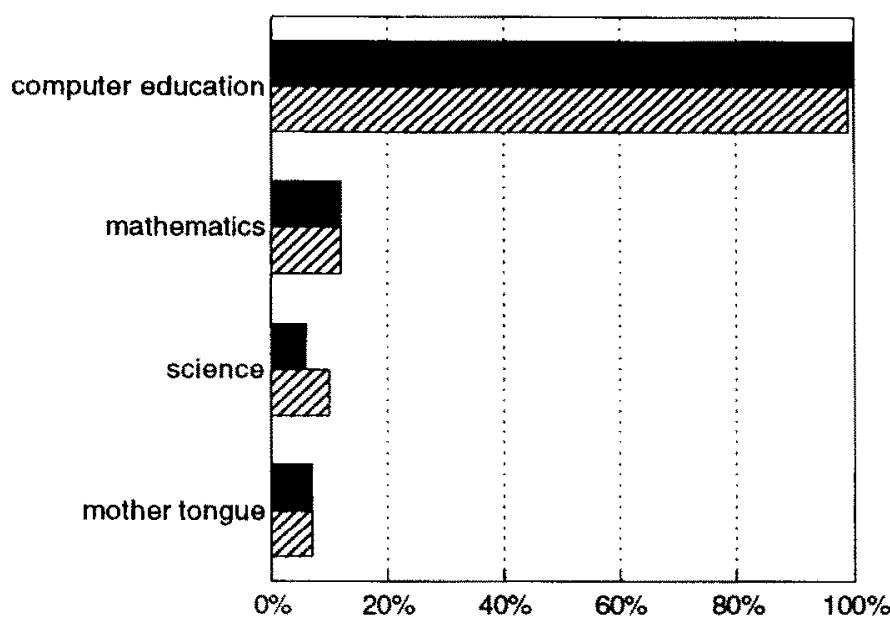

100-schools project $\bigotimes$ general sec. schools

Fig. 2. Percentage of teachers of subject areas using computers.

In the 1989, the year of data collection, the distribution of computer types is nearly the same in both groups. Most of the computers at the general secondary schools had an MS-DOS operating system ( $\mathrm{ca}$ ) $70 \%$ of all available computers), about $15 \%$ of the computers had a Z-80 processor and also about $15 \%$ of the computers had another 8-bit processor.

In the Comped study the computer coordinator in each school was asked about the availability of one or more programs for each of 23 computer applications. On average the schools from the 100 -school project had 14 programs and the other schools had 12 . This difference is significant $(P<0.05)$. Schools from the 100 -school project had more programs for painting/drawing, recreational games and tools/utilities, but not educational software such as tutorials and drill and practice. There was no difference between the groups in the average number of subjects (9) for which they had computer programs.

Computer implementation at school level can be seen as a measure of the outcome of introducing computers in schools. The degree of computer implementation can be represented by two indicators. The first indicates the use of computers for administrative purposes such as maintaining records about students, constructing and maintaining the timetable, financial matters and office word processing. The second indicates the percentage of teachers using computers for educational purposes.

The results show that in both groups nearly all schools use computers for administrative purposes.

In four subject areas (computer education, mathematics, science and mother tongue) data we collected from teachers about the use of computers for educational purposes. The results in Fig. 2 show that nearly all computer education teachers use computers during their lessons. At the schools from the 100 -school project as well as the other schools the integration of computer use in the existing subjects is low and there is no significant difference in the degree of computer implementation in any of the four subjects. In both groups computers were used during lessons for computer education, while the integration of computers in existing subjects is an activity of a rather small group of teachers.

\begin{tabular}{|c|c|c|}
\hline Problem & 100-school project & Other schools \\
\hline $\begin{array}{l}\text { Software } \\
\text { Time to learn about }\end{array}$ & 50 & 53 \\
\hline computers prepare lessons & 40 & 41 \\
\hline Hardware & 33 & 38 \\
\hline Financial support & 31 & 34 \\
\hline Knowledge & 26 & 31 \\
\hline
\end{tabular}


Table 3. School policies, as percent schools responding

\begin{tabular}{lcc}
\hline Policy & 100-school project & Other schools \\
\hline $\begin{array}{l}\text { Computer experience for all } \\
\text { students }\end{array}$ & 98 & 98 \\
$\begin{array}{l}\text { Computer course for } \\
\text { specific grades }\end{array}$ & 95 & 93 \\
Content of computer course & 85 & 82 \\
\hline
\end{tabular}

Although the profile of computer implementation in both groups of schools is the same, it may be hypothesized that due to the differences in support, earlier provision of hardware and in-service training during the innovation process, the schools participating in the 100-school project encountered other or fewer problems in using computers for educational purposes than the other schools. However, the principals in both groups mention the same problems as most serious in the process of introducing computers for educational purposes. The five most serious problems, from a list of 28 , mentioned by the principals are shown in Table 2 . On average both groups of schools mention eight different problems in using computers.

Also the policy schools were applying for using computers was almost the same in both groups. (Table 3). As mentioned before, the schools from the 100-school project had more programs for recreational games than other schools, which may be a characteristic for the early days of educational computing. $60 \%$ of the schools from the 100 -school project had formulated rules for the use of recreational games as part of the school policy. This is in contrast with the other schools where $48 \%$ had rules for playing educational games. Nearly $50 \%$ of the project schools had written down their policy for computer use in a document while this was done by $32 \%$ of the other schools.

In general the results show that 6 years after the 100 -school project took place, the schools that participated in this project, the early adopters, hardly differ from other schools in using computers. It is remarkable that the schools of the 100 -school project had more computers than the other schools until 1988 and that in 1989 this was reversed. In 1989, the use of computers for computer education was realized in almost all schools; it seems that the provision of hardware in the 100 -school project stimulated other schools not to stay behind but to acquire computers at their own initiative. Further, the type of computer use, namely mainly teaching a course in computer and information literacy, was considered by the other schools as an adequate model of computer use, as almost all schools followed this model. That the 100 -school project received computers at an earlier stage than other schools did not influence the degree of computer integration in existing subjects. The limited integration level of computers in existing subjects seems to have been caused by other aspects than the years of computer use, the provided hardware, software and in-service training.

\section{EVALUATION OF THE BASIC PROVISION OF SOFTWARE}

As part of the NIVO-project, to stimulate educational computer use, schools received, along with the hardware, a 'starter pack' of software consisting of a wordprocessor, spreadsheet, database and authoring language; also exemplery lesson ideas and applications were developed for this starter pack (see Table 1 for a short description). Also during the NIVO-project curriculum development for computer education and in-service teacher training were intensified; a beginning was made with courseware development, which was intensified in 1987 to a sizeable, 4-yr, national courseware development project. An intensive campaign accompanied the production of software and courseware in order to stimulate their dissemination and use. An important evaluation question for the NIVO-project is whether the donation of the starter pack to all schools contributed to the implementation of computers in the schools. Was the starter pack used, and what were its strengths and weaknesses?

The following results are based on questionnaires from 666 teachers working at 255 computerusing schools. The group of teacher respondents encompasses 407 teachers in the subjects mathematics, science and mother tongue who were not using computers for instructional purposes in their lessons. That these teachers indicated that they did use certain programs probably means that they used these programs outside lessons, for example for their own orientation or in other grades than those considered here. There were 201 computer computer-using teachers for the 


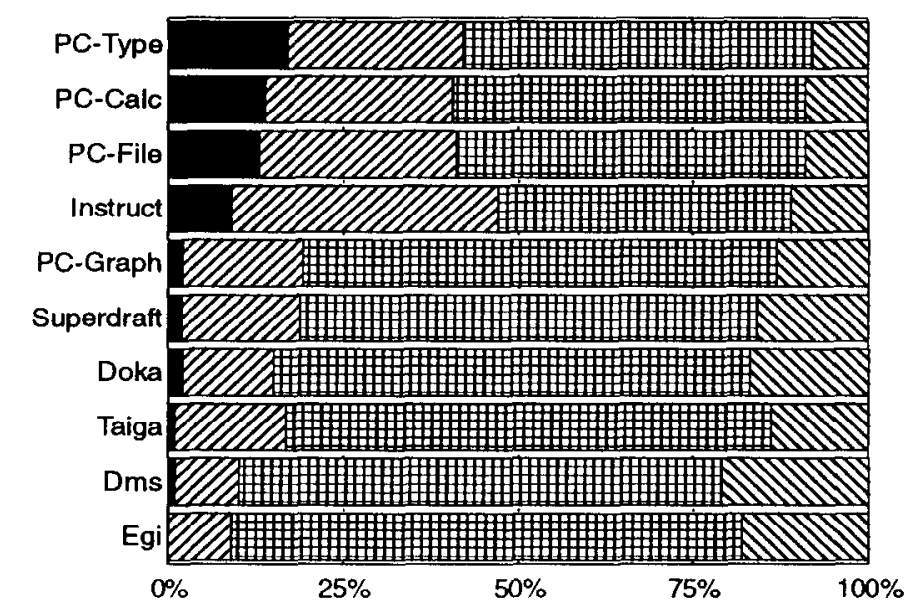

Used weekly or more $\square$ Used few times No use $\$$ Not available

Fig. 3. Availability and use of programs in the software-kit by teachers.

subject Information and Computer Literacy (ICL), and 58 computer-using teachers in the subjects mathematics, science and mother tongue.

As the patterns of use of the programs in the starter pack were not essentially different between the three groups of teachers, Fig. 3 contains only aggregated data about the availability and frequency of use of the software packages according to different groups of teachers.

Figure 3 shows that except for a few programs the software packages were very infrequently used. Especially remarkable is the substantial group of respondents indicating that certain programs were not available. This could have two meanings. First, as all schools could acquire the starter pack free of charge from a regional center, that some schools did not make efforts to get these packages. On the other hand it could mean that within schools the information provision about available software was poor.

A second evaluation question related to the starter pack is to what extent the example lesson ideas and applications were used by teachers. Figure 4 shows that only a small proportion of the teachers in existing subjects (mathematics, science and mother tongue) used this courseware. From Fig. 2 we know that only a very small group of teachers in these subjects was using the computer in their lessons, but it is remarkable that so few of them made use of courseware specifically developed for their subject. This small group of users, $2 \%$ of all the teachers in these subjects, was

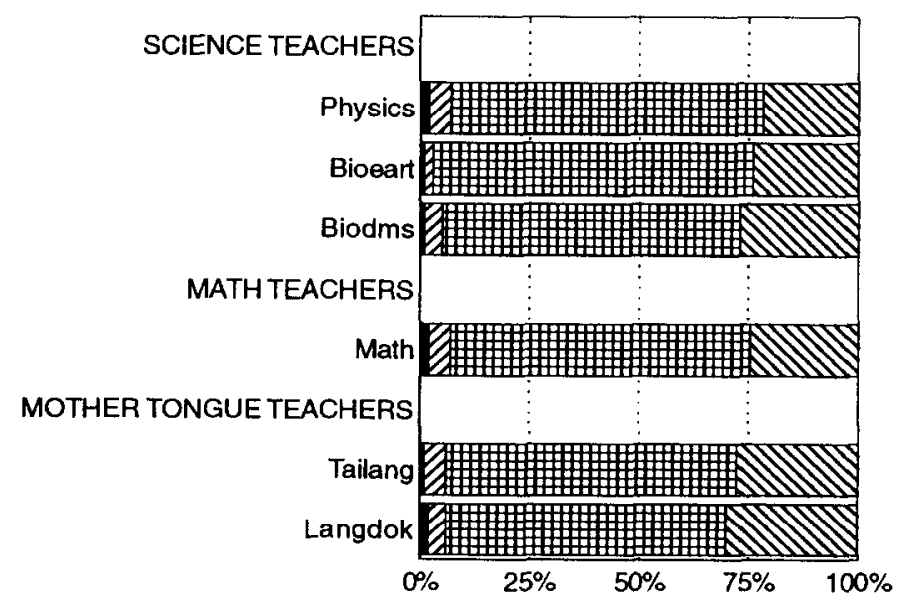

Used weekly or more $\square$ Used few times No use $\mathbb{N}$ Not available

Fig. 4. Availability and use of the lesson ideas by teachers. 
Table 4. Opinions of teachers about the courseware

\begin{tabular}{lccc}
\hline & \multicolumn{2}{c}{$\begin{array}{c}\text { Exist subject } \\
\text { teachers grade } 8\end{array}$} & \\
\cline { 2 - 3 } & $\begin{array}{c}\text { No } \\
\text { computer } \\
\text { use in } \\
\text { class }\end{array}$ & $\begin{array}{c}\text { Computer } \\
\text { use in } \\
\text { class }\end{array}$ \\
\cline { 2 - 3 } & $n=19$ & $n=9$ & \\
& $\begin{array}{c}n=28 \\
\text { Characteristics of lesson idea }\end{array}$ & $(\%)$ & $(\%)$ \\
\hline Stimulates computer use in class & 59 & 66 & 61 \\
Good example & 86 & 78 & 83 \\
Necessary for use of packages & 39 & 67 & 47 \\
Provides practical instruments & 75 & 85 & 77 \\
Clear student instructions & 68 & 84 & 72 \\
Not difficult to use & 60 & 85 & 67 \\
Stimulate students to learn & 84 & 67 & 79 \\
Clear educational goals & 67 & 71 & 64 \\
Clear student activities & 70 & 76 & 71 \\
Teaching and learning strategy & & & \\
applicable in my instruction pract. & 33 & 28 & 32 \\
Corresponding with curriculum & 31 & 68 & 40 \\
$\begin{array}{l}\text { Sufficient instr. for installation } \\
\text { slightly agree }\end{array}$ & 63 & 67 & 64 \\
Easy to use in class & 40 & 55 & 45 \\
\hline
\end{tabular}

asked to express their opinion about the courseware. Due to such a low proportion of teachers using the courseware, we present no percentages, but only the results for the group as a whole.

From Table 4 it can be concluded that teachers consider the courseware programs are good examples of computer use in class, well documented and motivating for students. However, teachers also rate the courseware as not corresponding very well with the content of the curriculum and difficult to integrate in their instructional practices.

\section{CONCLUSIONS AND DISCUSSION}

As a result of stimulation projects during a period of 4-6 years, computers were introduced in all schools for general secondary education. In 1989, computers were used mainly for teaching students about computers, which was one of the goals of the stimulation policy of the Dutch government. There were only a few teachers in existing subjects who used computers for instructional purposes.

There were several problems that hindered the progress of computer use in existing subjects. Educational practitioners mentioned the lack of high quality software as one of the main obstacles in using computers in existing subjects. However, our results suggest that this cannot be seen in isolation from other conditions such as the provision of information within schools. Besides that, many teachers indicated that they do not have enough time to explore the possibilities of computers for educational purposes or to prepare lessons in which computers are used. That many teachers mention this problem indicates that the available courseware was not tuned to the curriculum. One may conclude that national courseware development should result in integration of courseware in the curriculum and in textbooks.

Finally, it seems that the hardware infrastructure, the location, number and configuration of computers, that was provided to schools via the NIVO project was adequate for lessons in Information and Computer Literacy but less adequate for teachers who wanted to integrate computers regularly in their instructional practice. In the short term we cannot expect schools to create a situation in which all pupils, individually or in pairs have continuous access to a computer. A consequence of this hardware infrastructure is that schools need to explore more whole class use of computers, such as for demonstration, for database applications, etc, while individual use of computers can be planned only for a limited number of situations.

The lessons that can be learned from the Dutch stimulation projects are: (1) the conditions for the introduction of computer use as a separate subject are not sufficient to realize the integration of computer use in existing subjects; (2) courseware development for computer use as an aspect 
of existing subjects needs to be tuned to the curriculum (3) the didactical and organizational aspects of computer use needs to be part of teacher training; (4) at school level provisions for whole class use need to be made such as one computer per classroom, or computers on wheels.

\section{REFERENCES}

1. Pelgrum W. J. and Plomp Tj., The Use of Computers in Education Worldwide. Pergamon Press, Oxford (1991).

2. Krins D. P. M., Plomp Tj. and Scholtes H. H. M., New technology in education in The Netherlands. Report to the European Commission, Task Force Human Resources, Education, Training and Youth (1992). 